\title{
Randomized Controlled Parallel-Design Clinical Study of the Efficacy and Safety of Intranasal Interferon gamma in Treatment of Influenza-Like Infections
}

\author{
Ivan I. Tokin, $\mathrm{PhD}^{1,2}$; Vladimir V. Nikiforov, $\mathrm{PhD}, \mathrm{ScD}^{3}$; Pavel I. Shabalkin, $\mathrm{PhD}^{4}$; \\ Pavel V. Pimanchev ${ }^{5}$; Julia A. Isakova, PharmD ${ }^{6}$; Valeriy V. Tsvetkov, $\mathrm{PhD}^{1}$ \\ ${ }^{1}$ Research Institute of Influenza, Saint Petersburg, Russia \\ ${ }^{2}$ North-Western State Medical University named after I.I. Mechnikov, Saint Petersburg, Russia \\ ${ }^{3}$ Pirogov Russian National Research Medical University, Moscow, Russia \\ ${ }^{4}$ N.N. Blokhin National Medical Research Center of Oncology, Moscow, Russia \\ ${ }^{5}$ Sechenov First Moscow State Medical University, Moscow, Russia \\ ${ }^{6}$ Scientific Clinical Centre of the Russian Railways, Moscow, Russia
}

\begin{abstract}
Background: Influenza is a highly variable infection that can cause fatal complications. Universal approaches, such as general stimulation of the immune system to activate its natural antiviral capacities, seem to be a rational measure.

Methods: A total of 410 patients with influenza-like infections (ILI) were randomly assigned to one of three treatment groups and one control group. Interferon gamma (IFN- $\gamma$ ) was administered by intranasal introduction of 1 to 3 drops into each nostril 5 times per day daily for 5 days. The first dose of investigational medicine was given within $48 \mathrm{~h}$ of the onset of the influenza-like symptoms. One drop of the solution contains 1,000 IU of active substance. All patients received basic complex therapy without any antiviral or immunomodulating agents. The patients were followed up for 7 days. Treatment efficacy was evaluated by the mean duration of symptoms (MDS), the period of viral antigen detection (VAD) measured after 1-2 and 4-5 days of treatment, and the incidence of complications. We used conventional indicators to evaluate the safety of IFN- $\gamma$ in the treatment of ILI.

Results: The administration of 2 or 3 drops of IFN- $\gamma$ in each nasal passage led to better outcomes manifested in the considerable $(P<0.05)$ reduction of all acute respiratory symptoms, and therefore to a more rapid recovery. In these treatment groups, statistically significant decreases for MDS values, VAD period, and incidence of complications were registered. Intranasal IFN- $\gamma$ in complex therapy of ILI was considered to be well tolerated and safe.(International Journal of Biomedicine. 2018;8(4):327-322.)
\end{abstract}

Key Words: Influenza $\bullet$ interferon gamma $\bullet$ respiratory tract infection $\bullet$ antiviral capacities

\section{Abbreviations}

ARTI, acute respiratory tract infections; ILI, influenza-like infections; MDS, the mean duration of symptoms; VAD, viral antigen detection.

\section{Introduction}

Interferon gamma (IFN- $\gamma$ ) is an antiviral and immunomodulating drug that prevents and treats ARTI caused by influenza or other viral respiratory infections. The IFN- $\gamma$ activity against influenza virus infection, herpes simplex virus, HPV, and HIV, as well as against tuberculous and urogenital infections has been described in many studies. The mechanism of its antiviral action has been discovered, and antiviral properties have been shown in a range of preclinical and clinical studies. ${ }^{(1-6)}$

Influenza can be a very dangerous disease; it can lead to life-threating complications and death, especially in patients of risk groups. ${ }^{(7)}$ The disease is caused by influenza viruses (the basic types are A, B, and C). Type A can cause serious complications and global pandemics. It has been detected in 
the majority of clinical cases, and the subtype H3N2 generally dominates. Type B can also cause a rather severe infection; however, it never breaks out into a worldwide epidemic. Type $\mathrm{C}$ usually leads to mild acute respiratory tract disease.

According to the WHO reports, influenza takes the lives of up to 500,000 people around the world every year and potentially can kill millions of people. For instance, it affected half of the world's population in 1918 and caused the death of around 50 million people. Since the pandemic of 2009, type A influenza (mainly H1N1 and H3N2 subtypes) and type B influenza cause global co-infections every year with a high risk of dangerous complications. ${ }^{(8-10)}$

According to the Federal Service for Supervision of Consumer Rights Protection and Human Welfare, the mortality from influenza in 2017-2018 in Russia was around 70 people. Despite the reported decrease of mortality due to effective and widespread vaccination, which encompasses almost $60 \%$ of the country's population, the problem is not solved and the current results are not satisfying. From October to April, influenza still causes vast waves of affected patients, sick leaves, and hospital stays. ${ }^{(11)}$

The main difficulty is rapid mutations of the influenza virus. Every year, new strains appear and circulate in the population in different combinations. This significantly complicates the quick data collection necessary to make an effective vaccine; therefore, vaccination can rarely protect people. ${ }^{(12-14)}$

Another challenge is that alongside the influenza viruses, so-called «imitators» (the viruses of parainfluenza, adenoviruses, respiratory syncytial virus (RSV), coronavirus, etc.) could be a reason for acute respiratory tract disease. However, during the epidemic season more than $50 \%$ of upper respiratory tract infections are usually associated with influenza viruses. ${ }^{(15)}$

Today, influenza and other ARTI with similar clinical symptoms are commonly referred to as ILI. Since 2011, ILI has been defined as an acute respiratory illness with a measured temperature of $38^{\circ} \mathrm{C}$ or higher, and cough, with onset within the last 10 days. Although early clinical diagnosis of influenza is still a big challenge, this approach helps to detect influenza illness and distinguish it from other types of ARTI despite of non-specific and common symptoms, like fever. ${ }^{(10,16)}$

This article describes the results of a phase II, evidencebased clinical trial conducted to assess the efficacy of intranasal IFN- $\gamma$ administered in several treatment schemes against ILI. The aim of the study was to evaluate the tolerability, safety, and efficacy of various treatment regimens of intranasal IFN- $\gamma$ in complex therapy of adult patients with ILI.

The investigational drug has passed preclinical studies and phase I clinical trials. The study was performed in accordance with good clinical practice, with permission of the national regulatory authority, and under the approval of the Local Ethics Committee.

\section{Materials and Methods}

We conducted a randomized, controlled, paralleldesign clinical trial. A total of 410 patients (mean age, 29.942.6 years) with ILI were examined prospectively, screened for inclusion, and recruited in one center if they satisfied the criteria (Table 1). The participants were enrolled during the period when influenza was announced to be present in the community (autumn-winter, 2005-2006). All participants provided the written informed consent.

Table 1.

Inclusion and exclusion criteria

\begin{tabular}{|c|l|l|}
\hline No. & Inclusion criteria & \multicolumn{1}{|c|}{ Exclusion criteria } \\
\hline 1 & $\begin{array}{l}\text { Men and women } \\
18 \text { to 60 y.o. }\end{array}$ & Pregnancy or lactation \\
\hline 2 & $\begin{array}{l}\text { Clinical symptoms } \\
\text { of ARTI }\end{array}$ & $\begin{array}{l}\text { Previous therapy with antitumor or } \\
\text { immunomodulating drugs }\end{array}$ \\
\hline 4 & $\begin{array}{l}\text { Early stage of the } \\
\text { disease (1-2 days) } \\
\text { pregnancy } \\
\text { test (for women) }\end{array}$ & $\begin{array}{l}\text { Serious mental disorders that require } \\
\text { treatment with antidepressants, major } \\
\text { tranquilizers, hospitalization, or resulted } \\
\text { in disability }\end{array}$ \\
\hline 5 & $\begin{array}{l}\text { Written informed } \\
\text { consent }\end{array}$ & $\begin{array}{l}\text { Diseases associated with immune system } \\
\text { disorders (autoimmune diseases); diabetes; } \\
\text { severe pulmonary, cardiovascular, renal } \\
\text { pathology and other diseases that, from } \\
\text { investigator's point of view, did not allow } \\
\text { the patient to participate in the study }\end{array}$ \\
\hline 6 & $\begin{array}{l}\text { Inability or unwillingness to give the informed } \\
\text { consent to participate in the study or to meet } \\
\text { the requirements of the study }\end{array}$ \\
\hline
\end{tabular}

All the patients were randomly assigned to one of three treatment groups and one control group: with interferon gamma administered by intranasal introduction of 3 drops into each nostril (Main group I, $\mathrm{n}=110$ ), of 2 drops into each nostril (Main group II, $\mathrm{n}=110$ ), of 1 drop into each nostril (Main group III, $\mathrm{n}=110$ ), and basic complex therapy without investigational drug (Control group, $\mathrm{n}=80$ ).

The investigational drug-IFN- $\gamma\left(\right.$ Ingaron ${ }^{\circledR}$, lyophilizate for the preparation of 100,000 IU solution for intranasal use, manufactured by PHARMACLON LLC, Russia, on the basis of patent No2214832) — was administered 5 times per day for 5 days. The first dose of investigational medicine was given within $48 \mathrm{~h}$ of the onset of the influenza-like symptoms. One drop of the solution contains 1,000 IU of active substance.

All patients received basic complex therapy, including expectorants, antipyretics (in cases of temperature of $\geq 38.5^{\circ} \mathrm{C}$ ), vitamins, and herbal inhalations, without any antiviral or immunomodulating agents. The patients were followed up for 7 days. The data on the concomitant therapy, including doses, frequency rates, course length, and names of drugs, were recorded.

Treatment efficacy was evaluated on the base of MDS, defined as the time from the first symptom onset to the last symptom release. Viral antigens were detected after 1-2 and 4-5 days of treatment. Incidence of complications was also assessed.

We used conventional indicators to evaluate the safety of IFN- $\gamma$ in the treatment of ILI (vital signs, adverse reactions, and clinical laboratory tests). These parameters were compared 
between the main groups and the control group. An adverse event was defined as any negative, unintended or unplanned effect (not only related to the investigational drug) on vital signs, symptoms, concomitant diseases, or laboratory parameters that changed after a patient had been enrolled in the study.

To evaluate efficacy and safety, subjective patient complaints were collected, and body temperature, blood pressure and pulse data were measured and recorded according to the study protocol. General blood and urine analyses were conducted before and after the treatment. All data were entered into individual case reports forms.

The etiology of the disease was established by immunofluorescence (IF) express-test with the identification of influenza, parainfluenza, RSV, adenovirus, and coronavirus infection. The IF analysis was repeated after 1-2 and 4-5 days of treatment. Specimens were collected from the upper respiratory tract (nasal passages) using swabs; blood and urine samples were prepared and tested in the local laboratory using routine methods.

Statistical analysis was performed using statistical software package SPSS version 17.0 (SPSS Inc, Chicago, IL). The normality of distribution of continuous variables was tested by the Kolmogorov-Smirnov test with the Lilliefors correction and Shapiro-Wilk test. Baseline characteristics were summarized as frequencies and percentages for categorical variables and as mean \pm standard deviation (SD) for continuous variables. A 95\% confidence interval was calculated. For data with normal distribution, inter-group comparisons were performed using Student's t-test. A probability value of $P<0.05$ was considered statistically significant. Baseline data (four sets) included demographic indicators, and time from the first symptom onset before the intervention.

\section{Results}

Baseline demographic characteristics of patients and the kind of virus are shown in Table 2.

Table 2.

Baseline characteristics of 410 patients with influenza symptoms enrolled into the study

\begin{tabular}{|l|c|c|c|c|}
\hline \multicolumn{1}{|c|}{ Baseline parameter } & $\begin{array}{c}\text { Main } \\
\text { group I } \\
\mathrm{n}=110\end{array}$ & $\begin{array}{c}\text { Main } \\
\text { group II } \\
\mathrm{n}=110\end{array}$ & $\begin{array}{c}\text { Main } \\
\text { group III } \\
\mathrm{n}=110\end{array}$ & $\begin{array}{c}\text { Control } \\
\text { group } \\
\mathrm{n}=80\end{array}$ \\
\hline Age & $42.6 \pm 4.6$ & $33.6 \pm 6.3$ & $31.9 \pm 4.2$ & $29.9 \pm 2.8$ \\
\hline Female & $37.8 \%$ & $37.8 \%$ & $53.6 \%$ & $48.8 \%$ \\
\hline Male & $62.2 \%$ & $62.2 \%$ & $46.4 \%$ & $51.2 \%$ \\
\hline Smoking status & $32.7 \%$ & $19.1 \%$ & $26.4 \%$ & $23.7 \%$ \\
\hline $\begin{array}{l}\text { Time from the 1st } \\
\text { symptom onset, h }\end{array}$ & $34 \pm 6.9$ & $38 \pm 7.2$ & $35 \pm 9.3$ & $37 \pm 6.3$ \\
\hline Influenza A (H1N1) & $15.5 \%$ & $14.8 \%$ & $17.6 \%$ & $15.8 \%$ \\
\hline Influenza A (H3N2) & $17.2 \%$ & $18.5 \%$ & $15.7 \%$ & $21.0 \%$ \\
\hline Influenza B & $10.3 \%$ & $9.2 \%$ & $2.0 \%$ & $2.6 \%$ \\
\hline RSV & $15.5 \%$ & $5.6 \%$ & $17.6 \%$ & $15.8 \%$ \\
\hline Adenovirus & $24.1 \%$ & $31.5 \%$ & $33.3 \%$ & $28.9 \%$ \\
\hline Parainfluenza I & $19.0 \%$ & $31.5 \%$ & $29.4 \%$ & $31.6 \%$ \\
\hline Coronavirus & $13.8 \%$ & $3.7 \%$ & $9.8 \%$ & $10.5 \%$ \\
\hline
\end{tabular}

At the beginning of the study, no significant differences were observed among the groups regarding age, sex, smoking status, and time from the first symptom onset. Distribution of severity of fever and other ILI symptoms before treatment were also comparable among the groups (Figures 1 and 2). The mean duration of the illness before receiving the first dose was 36 hours.

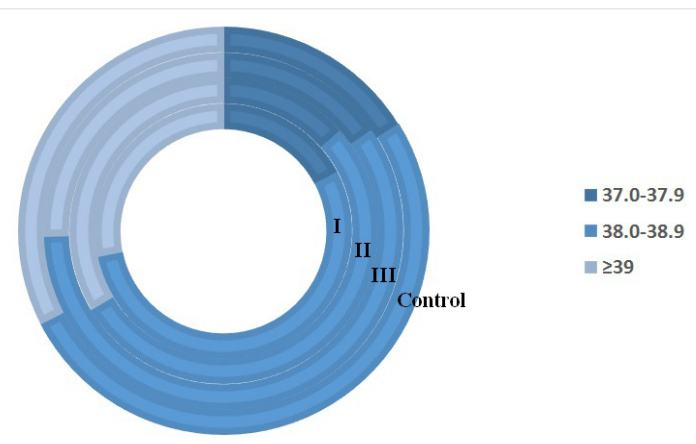

Fig. 1. Distribution of fever among patients with ILI before treatment.

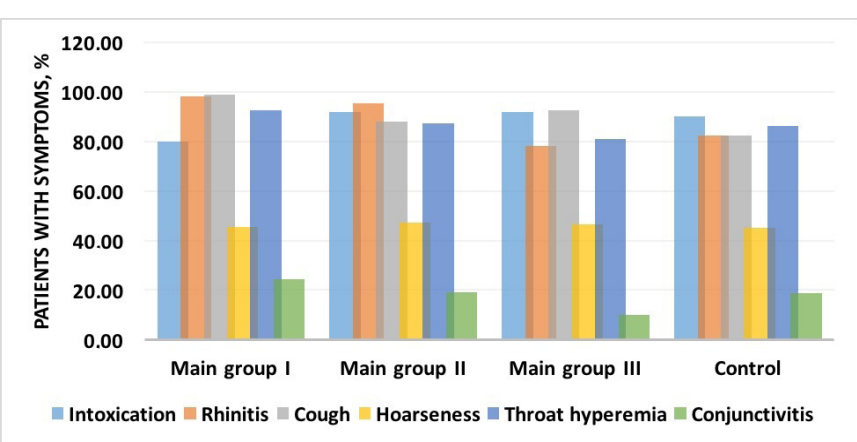

Fig. 2. Distribution of ILI symptoms among patients before treatment.

The obtained data showed that intranasal administration of IFN- $\gamma$ in any treatment regimen at the first 2 days after the onset of the disease symptoms resulted in statistically significant reduced fever and rhinitis. High temperature fell crucially after the first day of treatment in Main groups I and II, and after the second day it was lowered by a statistically significant amount in Main group III too, as compared to the Control group (Figure 3).

However, the administration of 2 or 3 drops of IFN- $\gamma$ in each nasal passage led to better outcomes manifested in the considerable $(P<0.05)$ reduction of all acute respiratory symptoms (fever, intoxication and catarrhal symptoms), and therefore to a more rapid recovery (Table 3 ).

Thus, in these treatment groups, statistically significant decreases for MDS values were registered: 2 times for fever, and 1.7 times for general intoxication. The VAD period (according to the results of the IF examination performed at 1-2 days and 4-5 days after the start of treatment) was dramatically shorter in Main groups I and II, and demonstrated a significant $(P<0.05)$ difference from the Control group after the first days of therapy (Figure 1). 


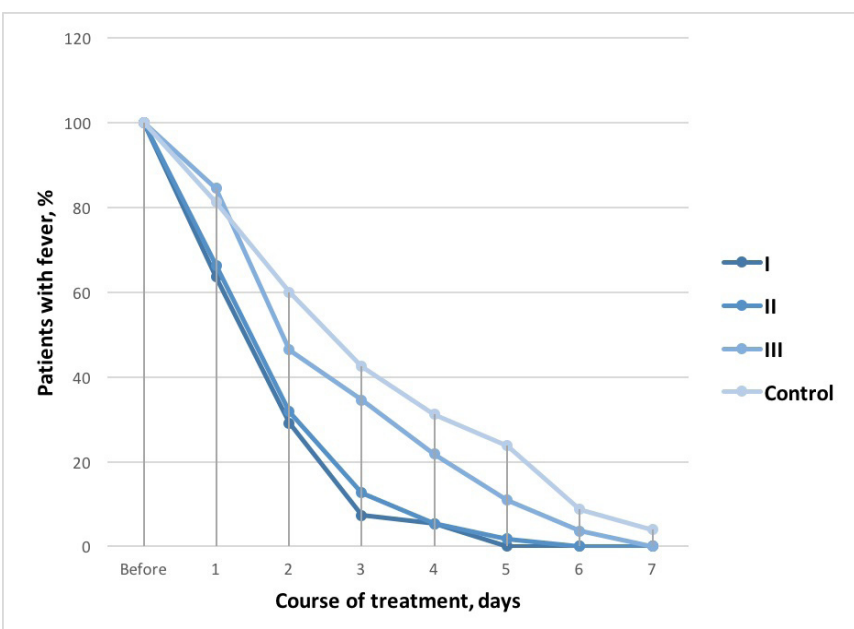

Fig. 3. Dynamics of fever among patients with ILI during the treatment.

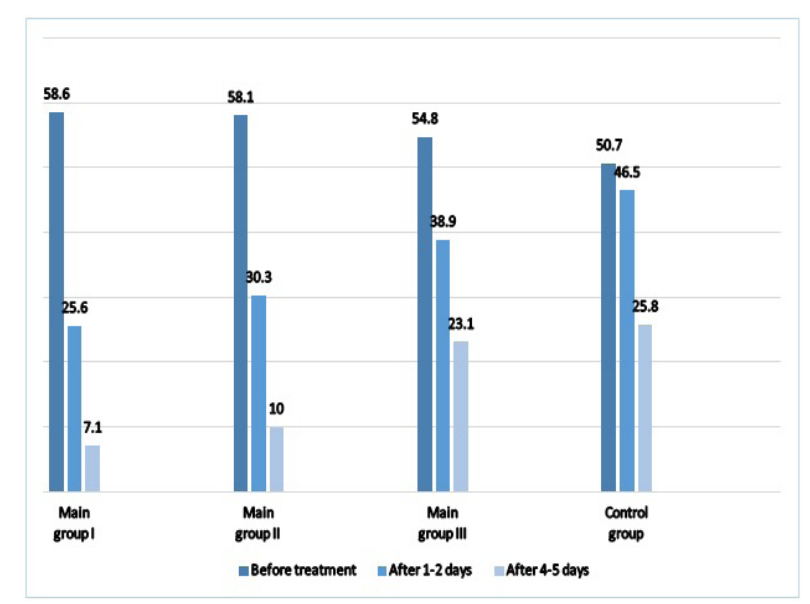

Fig. 4. The duration of VAD in the nasal passages of patients with ILI.

In general, the course of the disease was milder with half the number of complicated forms in Main groups I and II compared to the control patients (Table 4).
Table 4.

Frequency of complications in patients treated and not treated with IFN-y

\begin{tabular}{|l|c|c|c|c|c|c|}
\hline Group & $\begin{array}{c}\text { Complications } \\
(\%)\end{array}$ & \multicolumn{4}{|c|}{ Including: } & \multirow{2}{*}{ EI $^{\wedge}$} \\
\cline { 3 - 6 } & bronchitis & pneumonia & sinusitis & tonsillitis & \\
\hline $\begin{array}{l}\text { Main I } \\
\mathrm{n}=110\end{array}$ & 16.4 & 7.3 & 0 & 9.1 & 0 & $2.2 *$ \\
\hline $\begin{array}{l}\text { Main II } \\
\mathrm{n}=110\end{array}$ & 20.9 & 5.4 & 2.7 & 7.3 & 5.4 & $1.7 *$ \\
\hline $\begin{array}{l}\text { Main III } \\
\mathrm{n}=110\end{array}$ & 31.8 & 8.2 & 7.3 & 10.0 & 6.4 & 1.1 \\
\hline $\begin{array}{l}\text { Control } \\
\mathrm{n}=80\end{array}$ & 36.2 & 12.5 & 10.0 & 8.8 & 5.0 & - \\
\hline
\end{tabular}

$*_{-}-P<0.05$ - in relation to the control group

Efficacy index (EI) was calculated as follows: the number of patients with complicated forms in control to the number of patients with complicated forms in the treatment group. It means how many times lower the rate of complicated forms of disease occurred in each therapeutic group in comparison with the control group.

No subjects reported either adverse reactions or individual intolerance. No pathological changes in hematological parameters were registered. Patients presented no subjective complaints about poor tolerability of the drug. No allergic reactions were reported. Therefore, intranasal IFN- $\gamma$ in complex therapy of ILI was considered to be well tolerated and safe.

\section{Discussion}

IFN- $\gamma$, which is sometimes called immune interferon, is the most important proinflammatory cytokine. In the human body, it is produced by natural killer cells, CD4-Th1 cells and CD8 cytotoxic suppressor cells. IFN- $\gamma$ receptors are present in macrophages, neutrophils, natural killer cells, and cytotoxic T-lymphocytes. IFN- $\gamma$ activates effector functions of these cells, particularly, their antimicrobial activity, cytotoxicity, the production of cytokines, superoxide and nitrooxide radicals, and, therefore, destruction of intracellular pathogens. . $^{(1,4,17,18)}$

Table 3.

Results of efficacy evaluation of interferon gamma use to treat patients with ILI

\begin{tabular}{|c|c|c|c|c|c|c|c|}
\hline & \multirow{2}{*}{ Group } & \multirow{2}{*}{$\begin{array}{c}\text { Number of } \\
\text { patients }\end{array}$} & \multirow{2}{*}{ Fever } & \multicolumn{3}{|c|}{ Duration of symptoms, days } \\
\cline { 4 - 8 } & & Total & $\begin{array}{c}\text { Adynamia/ } \\
\text { anxiety }\end{array}$ & Headache & Rhinitis & Catarrhal symptoms \\
\hline Main I & 110 & $1.33 \pm 0.10^{*}$ & $2.18 \pm 0.16^{*}$ & $1.47 \pm 0.35^{*}$ & $1.00 \pm 0.15^{*}$ & $2.33 \pm 0.11^{*}$ & $3.11 \pm 0.78^{*}$ \\
\hline Main II & 110 & $1.38 \pm 0.15^{*}$ & $2.16 \pm 0.18^{*}$ & $1.28 \pm 0.19^{*}$ & $1.07 \pm 0.19^{*}$ & $2.93 \pm 0.45^{*}$ & $3.85 \pm 0.19^{*}$ \\
\hline Main III & 110 & $1.80 \pm 0.10^{*}$ & $3.71 \pm 0.34$ & $2.93 \pm 0.15$ & $1.67 \pm 0.59$ & $3.03 \pm 0.21 *$ & $5.95 \pm 0.68$ \\
\hline Control & 80 & $3.22 \pm 0.29$ & $3.78 \pm 0.26$ & $3.21 \pm 0.20$ & $1.64 \pm 0.33$ & $4.01 \pm 0.82$ & $6.33 \pm 0.70$ \\
\hline
\end{tabular}

$*_{-} P<0.05$ - in relation to the control group. 
In 1995, Tomoda et al. suggested an important role of IFN- $\gamma$ in the protection against influenza and other ARTI. At the first stage of the disease, endogenous IFN- $\gamma$ ensures topical inhibition of viral replication (at the entry port of infection), removal of infected cells, and protection of non-infected cells due to de novo interferon synthesis. However, the activity of endogenous interferons is often insufficient to eliminate the infection. The administration of exogenous intranasal IFN- $\gamma$ is justified for prophylaxis of infection in patients who have been exposed to an influenza virus, and for treatment of already infected patients, primarily in order to reduce the risk of dangerous complications. ${ }^{(19)}$

None of the currently available direct antiviral agents proved able to prevent severe complications of influenza. The amantadine group of medicines (amantadine, rimantadine) blocks the replication of type A viruses and is effective in $70 \%-90 \%$ of cases if administered as a prophylactic measure. At the same time, these agents have demonstrated up to $100 \%$ resistance since 2009. Additionally, the implementation of these drugs is limited because of side effects. On the other hand, neuraminidase inhibitors show their action when the infection has already attacked the organism and spread. However, the effect extends exclusively to influenza. ${ }^{(20)}$

IFN- $\gamma$ acts not only as a preventive drug protecting cells against viral agents, but at the same time modulates immune response of the infected cells.

The preventive efficacy of IFN- $\gamma$ in healthy adults has been demonstrated in a placebo-controlled clinical study, in which ILI incidence was reduced 2.2 times $(P<0.05)$ during the administration period, and 1.9 times $(P<0.05)$ within a onemonth follow-up period after the administration, compared to the control group. On the base of this study, a positive budget impact for the health care system was shown with a subsequent $43 \%$ reduction in the estimated economic burden of influenza accompanied by a decrease in direct and indirect economic losses. Thus, the results of budget impact analysis confirmed the inclusion of Ingaron into complex influenza therapy as a cost-effective measure. ${ }^{(21)}$

Preclinical in vitro research into IFN- $\gamma$ antiviral activity was conducted for the avian type of influenza (H5N2 subtype). Results showed a reduction in the cytopathic action of the avian influenza virus. Further studies are required to prove this data in humans.

It should be emphasized that the study described in the article recruited average-aged and healthy adults with no concomitant pathology. Our study was not aimed at investigating the effects of the drug on other groups of patients, including high-risk categories (children, pregnant women or elderly people). Further large-scale studies are required to confirm the obtained results in larger numbers of patients of all the ages and clinical conditions.

In conclusion, we have described the results of the clinical trial for treatment efficacy and safety evaluation of a range of daily doses of IFN- $\gamma$. The obtained data show that the inclusion of IFN- $\gamma$ in the complex therapy of ILI in the early period of the disease (up to 48 hours) in adults can decrease the period of clinical symptoms $(P<0.05)$, VAD $(P<0.05)$, the incidence of complications $(P<0.05)$ and, therefore, reduce the duration of the patient's stay on the sick-list.

Thus, IFN- $\gamma$ can be recommended for the treatment of ILI in the dose of 2-3 drops into each nasal passage 5 times per day daily for 5 days due to its high antiviral and detoxification efficacy.

\section{Conflict of interest} interests.

The authors declare that they have no competing

\section{Acknowledgements}

The study was supported by PHARMACLON LLC, Russia. Writing assistant - Polina I. Pekhtereva, PharmD.

\section{References}

1. Schroder K, Hertzog PJ, Ravasi T, Hume DA. Interferongamma: an overview of signals, mechanisms and functions. $\mathrm{J}$ Leukoc Biol. 2004;75(2):163-89.

2. Don ES, Emelyanova AG, Yakovleva NN, Petrova NV, Nikiforova MV, Gorbunov EA, et al. Dose-dependent antiviral activity of released-active form of antibodies to interferongamma against influenza A/California/07/09(H1N1) in murine model. J Med Virol. 2017;89(5):759-766. doi: 10.1002/ jmv. 24717.

3. Berri F, Haffar G, Lê VB, Sadewasser A, Paki K, Lina $\mathrm{B}$, et al. Annexin $\mathrm{V}$ incorporated into influenza virus particles inhibits gamma interferon signaling and promotes viral replication. J Virol. 2014;88(19):11215-28. doi: 10.1128/ JVI.01405-14.

4. Verhoeven D, Perry S, Pryharski K. Control of influenza infection is impaired by diminished interferon- $\gamma$ secretion by CD4 T cells in the lungs of toddler mice. J Leukoc Biol. 2016;100(1):203-12. doi: 10.1189/jlb.4A1014-497RR.

5. Zhu Y, Mou Q, Zhao B, Luo H, Zhi Y, Lan L, Jiang Y. [Recombinant influenza A virus NS2 protein inhibits the production of interferon in lung tissues of infected mice]. Xi Bao Yu Fen Zi Mian Yi Xue Za Zhi. 2015;31(12):1615-9. [Article in Chinese].

6. Theeten H, Mathei C, Peeters K, Ogunjimi B, Goossens H, Ieven M, Van Damme P, Cools N. Cellular Interferon Gamma and Granzyme B Responses to Cytomegalovirus-pp65 and Influenza N1 Are Positively Associated in Elderly. Viral Immunol. 2016;29(3):169-75. doi: 10.1089/vim.2015.0071.

7. Deeva EG, Sologub TV, Tikhonova EP, Krasnova EI, Konovalova NI, et al. [Clinical and laboratory characteristics of influenza in pregnant women in the epidemiological season of 2013-2014]. Epidemiologiya i Infektsionnye Bolezni. 2015; 20(5):4-10. [Article in Russian]

8. Knobler SL, Mack A, Mahmoud A, Lemon SM. The Threat of Pandemic Influenza: Are We Ready? Workshop Summary. National Academy of Sciences: Washington, DC; 2005.

9. WHO. Influenza virus infections in humans. October, 2018. https://www.who.int/influenza/human_animal_interface/ [Electronic resource]. (Reference date: November 07, 2018)

*Corresponding author: Julia A. Isakova. Leading researcher of the Scientific Clinical Centre of the Russian Railways, Moscow, Russia.E-mail: julia-isakova@mail.ru 
10. WHO Global Technical Consultation: global standards and tools for influenza surveillance. Geneva: World Health Organization; 2011. [Electronic resource]. http://apps.who. int/iris/bitstream/10665/70724/1/WHO_HSE_GIP_2011.1 eng.pdf (Reference date: October 07, 2018).

11. Federal State Statistics Service. Rosstat. [Electronic resource]. http:// www.gks.ru (Reference date: November 06, 2018).

12. Wong SS, Webby RJ. Traditional and new influenza vaccines. Clin Microbiol Rev. 2013;26(3):476-92. doi: 10.1128/CMR.00097-12.

13. Olson ZF, Sandbulte MR, Souza CK, Perez DR, Vincent AL, Loving CL. Factors affecting induction of peripheral IFN- $\gamma$ recall response to influenza A virus vaccination in pigs. Vet Immunol Immunopathol. 2017;185:57-65. doi: 10.1016/j. vetimm.2017.01.009.

14. Song L, Xiong D, Hu M, Kang X, Pan Z, Jiao X. Immunopotentiation of Different Adjuvants on Humoral and Cellular Immune Responses Induced by HA1-2 Subunit Vaccines of H7N9 Influenza in Mice. PLoS One. 2016 Mar 1;11(3):e0150678. doi: 10.1371/journal.pone.0150678.

15. Harrison P. Influenza or Influenza-like Illness: Does It Matter? Medscape Infectious Diseases February 16, 2018. [Electronic resource]. (Reference date: November 09, 2018) 16. Fitzner J, Qasmieh S, Mounts AW, Alexander B, Besselaar T,
Briand S, ey al. Revision of clinical case definitions: influenzalike illness and severe acute respiratory infection. Bull World Health Organ. 2018;96(2):122-128. doi: 10.2471/BLT.17.194514. 17. Kuriakose T, Tripp RA, Watford WT. Tumor Progression Locus 2 Promotes Induction of IFN- $\gamma$, Interferon Stimulated Genes and Antigen Specific CD8+T-Cell Responses and Protects against Influenza Virus. PLoS Pathog. 2015;11(8):e1005038.

18. Hayney MS, Henriquez KM, Barnet JH, Ewers T, Champion HM, Flannery S, Barrett B. Serum IFN- $\gamma$ induced protein 10 (IP-10) as a biomarker for severity of acute respiratory infection in healthy adults. J Clin Virol. 2017;90:32-37. doi: 10.1016/j.jcv.2017.03.003.

19. Tomoda T, Morita H, Kurashige T, Maassab HF. Prevention of influenza by the intranasal administration of cold-recombinant, live-attenuated influenza virus vaccine: importance of interferon-gamma production and local IgA response.Vaccine. 1995;13(2):185-90.

20. Jester BJ, Uyeki TM, Patel A, Koonin L, Jernigan DB. 100 Years of Medical Countermeasures and Pandemic Influenza Preparedness. Am J Public Health. 2018;108(11):1469-1472. doi: 10.2105/AJPH.2018.304586.

21. Plavinskiy SL, Shabalkin PA, Isakova JA. Budget impact analysis on the intranasal form of interferon-gamma. International Journal of Pharmaceutical Research. 2018;10(4):343-345. 